\title{
Size selectivity of a trammel net for oval squid Sepioteuthis lessoniana
}

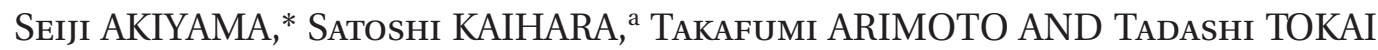 \\ Faculty of Marine Science, Tokyo University of Marine Science and Technology, Konan, Minato, \\ Tokyo 108-8477, Japan
}

\begin{abstract}
The size selectivity of a trammel net for herded oval squid Sepioteuthis lessoniana in Tateyama Bay, Chiba Prefecture, was estimated by comparison between the mantle length frequency distributions of oval squid caught by a trammel net and by a set net. The measured mesh sizes of the inner net of the trammel net and of the final section of the set net were 85.3 and $11.3 \mathrm{~mm}$, respectively. In the trammel net fishery where oval squid are herded into the net, most of the oval squid are caught in the bag-shaped inner net. Hence, the logistic function was employed for the size selectivity curve of the trammel net. The 'share each length's catch total' (SELECT) model was implemented for the estimation of the selectivity curve. The size selectivity $r(I)$ of the trammel net for the oval squid was expressed as a logistic function of the mantle length $l: r(I)=\exp (-18.57+0.88 I) /[1+$ $\exp (-18.57+0.88 \mathrm{I})]$. From these logistic parameter estimates, the $50 \%$ selection mantle length and selection range $\left(L_{75}-L_{25}\right)$ were calculated as 21.07 and $2.49 \mathrm{~cm}$, respectively. The selection probability of oval squid whose mantle girth was equivalent to the mesh perimeter of the inner net was 0.09. Accordingly, oval squid of a girth smaller than the mesh perimeter were likely to pass through the mesh to escape from the net.
\end{abstract}

KEY WORDS: oval squid, selectivity, 'share each length's catch total' (SELECT) model, set net, trammel net.

\section{INTRODUCTION}

In Tateyama Bay, Chiba Prefecture, trammel net fishery, in which oval squid Sepioteuthis lessoniana are herded into a net, is carried out from June to July. ${ }^{1,2}$ In this type of fishery, the fisherman on the boat repeatedly throws a metallic bar tied with rope into the sea to frighten the oval squid toward the trammel net. ${ }^{2}$ The oval squid are also caught by set net fishery in Tateyama Bay. The set net has a bag net mesh, which is small enough to retain small squid, as non-selective fishing gear, and hence its catch is considered to represent the size frequency distribution of the oval squid population in the fishing ground. ${ }^{3,4}$ The size selectivity of fishing gear can be estimated by comparison between the size frequency distributions of catches by the fishing gear (termed the test gear) and by nonselective control gear on the same fishing ground. For example, the size selectivity of a longline was

\footnotetext{
*Corresponding author: Tel: 81-3-5463-0475. Fax: 81-3-5463-0360. Email: akiyama@s.kaiyodai.ac.jp aPresent address: National Federation of Fisheries Co-operative Associations, Chiyoda, Tokyo 101-8503, Japan.

Received 3 February 2004. Accepted 4 June 2004.
}

estimated by comparison of the size frequency distributions of catches by the test gear with those of a trawl on the assumption that the trawl is nonselective for the size range in question because it has a codend with a small enough mesh. ${ }^{5,6}$ Furthermore, Tokai and Ueta ${ }^{3}$ and Ueta ${ }^{4}$ estimated the size selectivity of a squid jig for oval squid by comparing the mantle length frequency distributions of catches by the squid jig and a set net on the assumption that the set net is a non-selective fishing gear because its final trap has a small enough mesh size. In contrast, the size selectivity of trammel nets has been estimated in fishing experiments using nets of different mesh sizes ${ }^{7-12}$ and in tank experiments containing fish of known body size distributions. ${ }^{13-14}$ However, to date, there are no examples in which the size selectivity of a trammel net has been estimated by a comparison in size frequency distribution of catches between test gear and non-selective control gear. The trammel net is a commonly used fishing method in the coastal waters of Japan, ${ }^{1,2}$ and the oval squid is a major target species for Japanese coastal fishery. ${ }^{3,4}$ The present study presents the size selectivity of a trammel net for herded oval squid estimated from a comparison of the mantle length distributions in catch by trammel net with those by set net. 


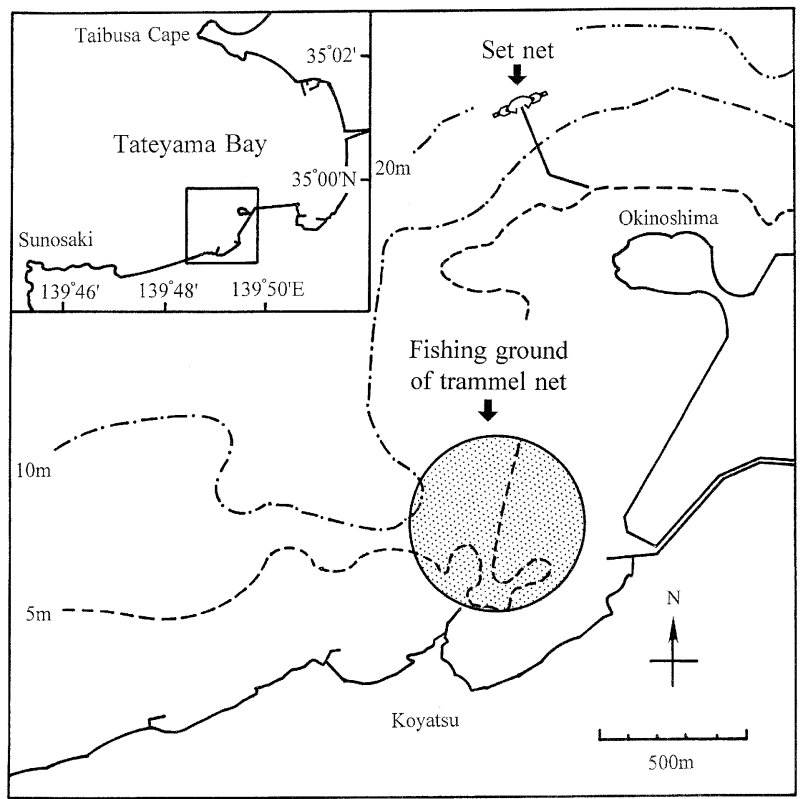

Fig. 1 Trammel net and set net fishing grounds in Tateyama Bay, Chiba Prefecture.

\section{MATERIALS AND METHODS}

\section{Fishing methods and data collection}

The oval squid were sampled in a trammel net and in a set net, both of which were operated by the same fisherman in the Koyatsu area, Tateyama Bay, Chiba Prefecture. The fishing grounds of the trammel net and the set net are shown in Figure 1. The trammel net was operated in the sandy or eelgrass bed area in 4- to 12-m-deep water in front of the Koyatsu Fishing Port. The set net was located $1 \mathrm{~km}$ north, off the trammel net fishing ground, and its main net was set at a depth of $18 \mathrm{~m}$.

The gear specifications of the trammel net ${ }^{2}$ and the set net are shown in Figure 2. The trammel net consisted of a single-layered net on the upper side and a triple-layered net on the lower side. The total length was $390 \mathrm{~m}$ and the net height was $3.2-4.1 \mathrm{~m}$. The average measured mesh sizes and standard deviation of 100 randomly sampled meshes were $85.3 \pm 0.5 \mathrm{~mm}$ and $360.7 \pm 2.5 \mathrm{~mm}$ in the inner net and outer net of the triple-layered net, respectively. The haul number per day of the trammel net was, on average, 4.5 hauls. The trammel net was usually operated in the daytime and its operation process could be divided into three stages. First, the trammel net was set on the seabed. Second, the oval squid were herded toward the trammel net using a metallic bar thrown repeatedly into the sea. Finally,
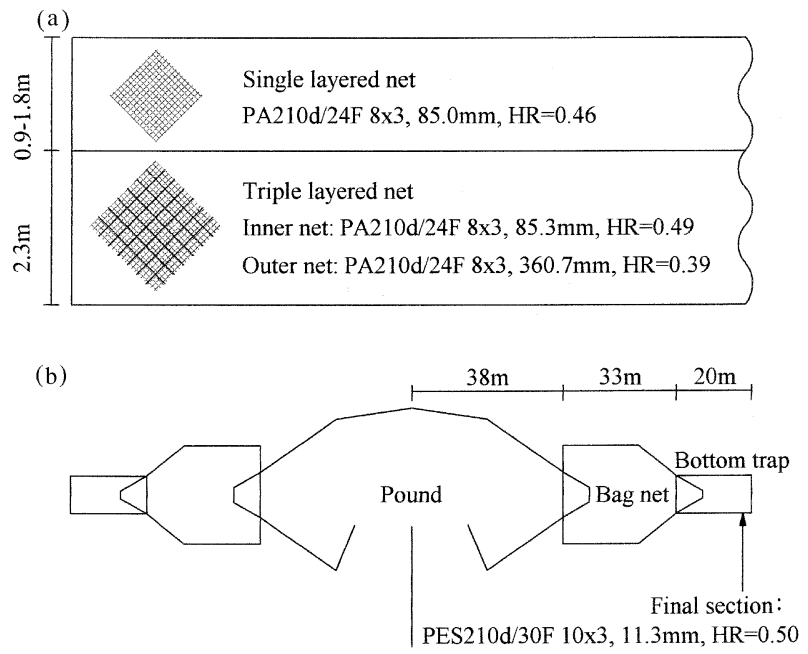

Fig. 2 (a) Trammel net gear specifications and (b) set net gear specifications.

the trammel net was hauled up on the deck. One operation (from setting the net to hauling it) took approximately $50 \mathrm{~min}$.

The set net consisted of a leader net and a main net. The main net had a pound with two side entrances and two bottom traps on both sides of the pound. The length of the leader net and the main net were 330 and $182 \mathrm{~m}$, respectively. The average measured mesh size and standard deviation of 100 randomly sampled meshes was $11.3 \pm 0.3 \mathrm{~mm}$ in the final section of the bottom traps. The bottom traps of the set net were hauled once a day at approximately 04.00 hours.

The trammel net was operated from 1 June to 31 July 2002 and from 1 June to 31 July 2003, and the mantle lengths of all of the oval squid caught by trammel net and by set net were measured on the fishing boats. The mantle girths of some of the oval squid were also measured. Mantle length and girth were measured to the nearest lowest centimeter with a tape measure.

\section{Estimation of size selectivity}

Size selectivity of fishing gear can be estimated by comparison of the size frequency distributions of oval squid caught by test gear and by non-selective control gear on the same fishing ground..$^{3-6}$ As mentioned above, the set net has a bottom trap with a mesh size of $11.3 \mathrm{~mm}$, which is small enough to be considered non-selective fishing gear, and its catch represents the size frequency distribution of the oval squid population in the 
fishing ground. ${ }^{3,4}$ Furthermore, according to the results of tag-recapture experiments, ${ }^{4}$ migration distance from the release to the recapture site of oval squid ranged from 1.6 to $14.8 \mathrm{~km} 1$ week after release, and one squid was recaptured $1.6 \mathrm{~km}$ from the release site just 1 day after release. These results imply that a distance of $1 \mathrm{~km}$ between the trammel net fishing ground and the set is not far, compared with the oval squid migration area, and therefore it can be assumed that the two fishing methods catch the same oval squid population. Consequently, in the present study, the size selectivity of the trammel net for oval squid was estimated by comparison of the mantle length frequency distributions in catch by the trammel net as the test gear with those of the set net as the control gear. The 'share each length's catch total' (SELECT) model was implemented for estimation of the selectivity curve. ${ }^{15-19}$

Here, it is necessary to examine the combination of the mantle length data in 2002 and 2003. Uchida et al. showed the conditions under which several sets of data could be combined for the SELECT model if the following conditions apply: (i) there is no change in the size frequency distribution of the target population during the experimental periods; and (ii) the ratio of the fishing effort of the test gear to that of the control gear is constant during the experimental periods. ${ }^{20}$ Growth of the oval squid depends on the accumulated water temperature, and year-class abundance of oval squid has been shown to fluctuate with the environmental factors of the previous year. ${ }^{4}$ Accordingly, a difference in the mantle length frequency distributions between the two years is possible. In fact, there was a significant difference between 2002 and 2003 in the average mantle length of the oval squid caught by the set net ( $t$-test, $P<0.05)$. Furthermore, the ratio of the haul number of the trammel net to that of the set net was also different between the two years. In the present study, therefore, the 2002 and 2003 data are not combined.

There is still a possibility that the curve parameters in the size selectivity of the trammel net were constant in 2002 and 2003, because the gear specifications were the same in the two years. Therefore, in the present study, based on the methods of Tokai and $\mathrm{Ueta}^{3}$ and Uchida et al., ${ }^{20}$ the data were applied to the following two models: model A, a single curve can express size selectivity in both of the two years; model B, two different curves are required to express size selectivity for each year.

In the SELECT model, the proportion $\phi_{i l}$ of the catch of size $l$ taken by the test gear to the total catch in year $i(i=1,2)$ is expressed by the following equation:

$$
\phi_{i l}=\frac{n_{i l}}{N_{i l}+n_{i l}}
$$

where $N_{i l}$ and $n_{i l}$ denote the catch number of oval squid of mantle length $l$ caught in year $i$ by set net and by trammel net, respectively. Here, $p_{i}$ denotes the proportion of $l$-length squid encountering the trammel net in year $i$, and the proportion of $l$ length squid entering and being retained in the set net is given by $1-p_{i}$. In model A and model $\mathrm{B}$, the proportion of the catch by trammel net to the total catch in year $i$ is described by parameter $p_{i}$ and a function of $l$ for size selectivity as follows:

$$
\begin{aligned}
& \text { model A: } \phi_{i}(l)=\frac{p_{i} \cdot r(l)}{1-p_{i}+p_{i} \cdot r(l)} \\
& \text { model B: } \phi_{i}(l)=\frac{p_{i} \cdot r(l)}{1-p_{i}+p_{i} \cdot r(l)}
\end{aligned}
$$

where $r_{i}(l)$ is the selectivity curve function of the trammel net for oval squid of mantle length $l$ in year $i$.

In general, a bell-shaped curve is usually employed for gill net and trammel net selectivity, ${ }^{7-14}$ because selection probability declines for larger fish. However, in trammel net fishery, where oval squid are herded into the net as previously reported, ${ }^{2}$ most of the oval squid are caught in the bag-shaped inner net and therefore larger squid are retained. This means that selection probability does not decline for larger squid. Hence, a logistic function was employed for the size selectivity of the trammel net similar to the trawl net. The selection curve for the trammel net for oval squid in year $i$ for model B can be used as follows:

$$
r_{i}(l)=\frac{\exp \left(a_{i}+b_{i} l\right)}{1+\exp \left(a_{i}+b_{i} l\right)}
$$

and that in two years for model A:

$$
r(l)=\frac{\exp (a+b l)}{1+\exp (a+b l)}
$$

where $a_{i}, b_{i}, a$ and $b$ are the parameters of the logistic function to be estimated. These parameters as well as $p_{1}$, and $p_{2}$ are determined using maximum likelihood methods. ${ }^{21,22}$ The log-likelihood to be maximized is as follows:

$$
\ln L=\sum_{i} \sum_{l}\left\{\ln \frac{\left(n_{i l}+N_{i l}\right) !}{n_{i l} ! N_{i l} !}+n_{i l} \ln \phi_{i}(l)+N_{i l}\left[1-\phi_{i}(l)\right]\right\}
$$

Solver on MS-Excel was used for maximization of the log-likelihood function. ${ }^{22}$

Akaike's information criterion (AIC) ${ }^{21}$ was used for selecting a better-fit model as follows:

$$
\mathrm{AIC}=-2 \mathrm{MLL}+2 k
$$


where MLL and $k$ denote the maximum log-likelihood and the number of parameters in each model, respectively. The model with the smaller AIC is the better-fit model.

\section{RESULTS AND DISCUSSION}

The catch number and mantle length of oval squid caught by trammel net and the set net in 2002 and 2003 are shown in Table 1. The catch numbers of oval squid over the haul number in trammel net and set net were 846/190 and 255/48 in 2002, and $645 / 173$ and $265 / 55$ in 2003, respectively. The mantle length range of oval squid caught by set net was wider than that of oval squid caught by trammel net in both years. The average values of mantle length of oval squid caught by trammel net were significantly larger than those of oval squid caught by set net in the two years ( $t$-test, $P<0.05)$. In addition, although there was no significant difference between 2002 and 2003 in the average mantle length of oval squid caught by trammel net ( $t$-test, $P>0.05)$, a significant difference was found in the average mantle length of oval squid caught by set net between 2002 and 2003 ( $t$-test, $P<0.05$ ).

The mantle length frequency distributions of oval squid caught by trammel net and set net are shown in Figure 3. Although the mantle lengths of oval squid caught by set net ranged from 12 to $51 \mathrm{~cm}$ in 2002 and from 13 to $48 \mathrm{~cm}$ in 2003, oval squid smaller than $17 \mathrm{~cm}$ in 2002 and $19 \mathrm{~cm}$ in 2003 were not caught by the trammel net. This implies that a trammel net with a larger mesh size has size selectivity for oval squid.

The fits of the estimated curves using models A and $B$ for the observed proportions of the catch by trammel net versus the total catch are shown in Figure 4 . The observed values had a large variation in some length classes larger than $30 \mathrm{~cm}$ because of the low sample number, and rose steeply with the increase in mantle length from 15 to $23 \mathrm{~cm}$ as a sigmoidal curve. The curves estimated by the models fitted the observed values well. The result supports the hypothesis that the size selectivity of the trammel net is described by a logistic function.

Estimates of the logistic parameters obtained from the SELECT model are shown in Table 2. In model A, the selection curves in 2002 and 2003 were expressed with a single curve function. In model B, different estimates of parameters $a$ and $b$ were estimated for 2002 and 2003. Parameter $p$ in 2002 was larger than in 2003 for both models. The reason for this is because the ratio of the haul number of the trammel net to that of the set net in 2002 was higher than in 2003 (Table 1). Values of AIC

Table 1 Catch number and mantle length of oval squid caught by trammel net and set net in 2002 and 2003

\begin{tabular}{lccccc}
\hline & \multicolumn{2}{c}{2002} & & \multicolumn{2}{c}{2003} \\
\cline { 2 - 3 } & Trammel net & Set net & & Trammel net & Set net \\
\hline Haul no. & 190 & 48 & & 173 & 55 \\
Catch no. & 846 & 255 & & 645 & 265 \\
Mantle length & $17-50$ & & & & $12-51$ \\
$\quad$ Range $(\mathrm{cm})$ & $28.0 \pm 5.8$ & $24.3 \pm 5.6$ & & $28.0 \pm 5.8$ & $26.0 \pm 6.5$ \\
$\quad$ Average \pm standard deviation $(\mathrm{cm})$ & & &
\end{tabular}

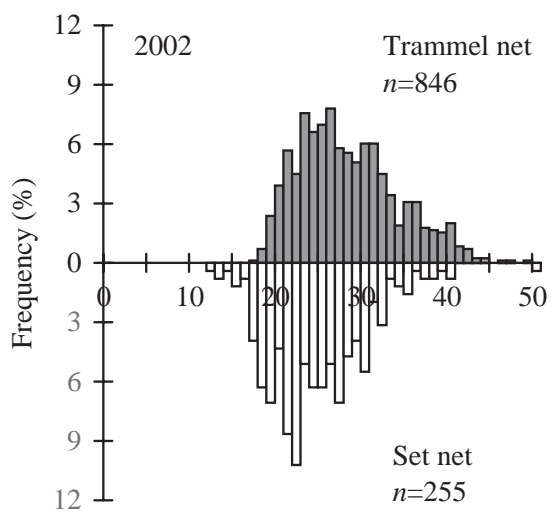

Mantle length $(\mathrm{cm})$

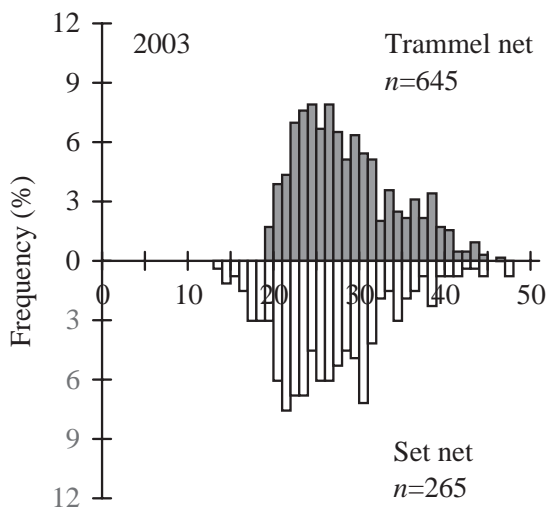

Mantle length $(\mathrm{cm})$
Fig. 3 Mantle length frequency distributions of oval squid caught by trammel net and set net in 2002 and 2003. 
Fig. 4 Estimated versus observed catch by trammel net as a proportion of the total catch. $(\bigcirc)$ Observed values.
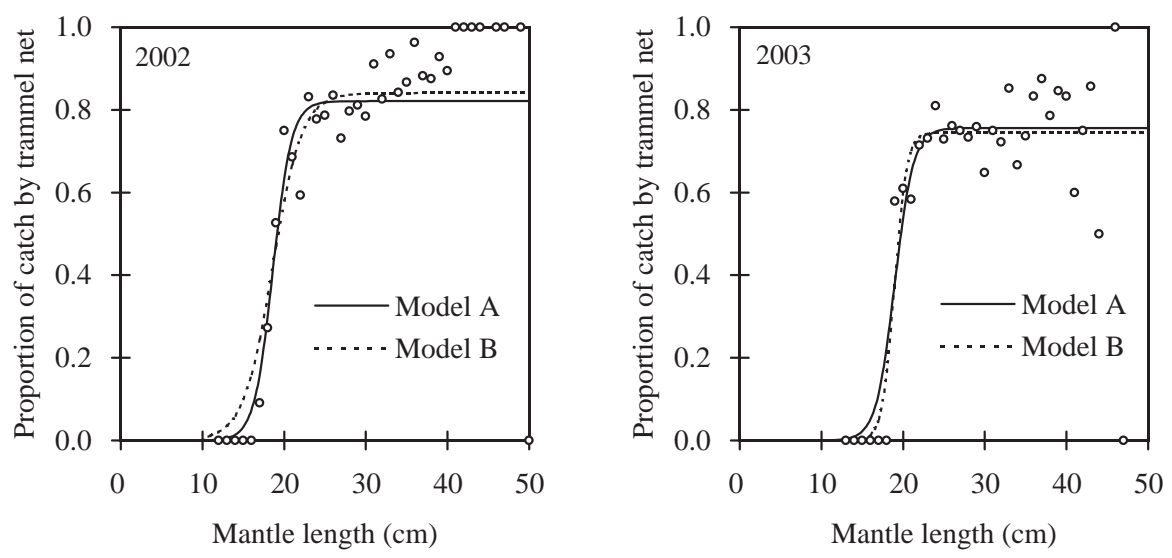

Table 2 Estimates of the logistic parameters $a, b$ and $p$ obtained in the 'share each length's catch total' (SELECT) model for the trammel net

\begin{tabular}{|c|c|c|c|c|}
\hline & \multicolumn{2}{|c|}{ Model A } & \multicolumn{2}{|c|}{ Model B } \\
\hline & 2002 & 2003 & 2002 & 2003 \\
\hline$a$ & \multicolumn{2}{|c|}{-18.57} & -12.26 & -26.98 \\
\hline$b$ & \multicolumn{2}{|c|}{0.88} & 0.55 & 1.32 \\
\hline$p$ & 0.82 & 0.76 & 0.84 & 0.75 \\
\hline MLL & -66.18 & -59.64 & -65.05 & -58.92 \\
\hline $\mathrm{AIC}$ & \multicolumn{2}{|c|}{259.64} & \multicolumn{2}{|c|}{259.93} \\
\hline$L_{50}(\mathrm{~cm})$ & \multicolumn{2}{|c|}{21.07} & 22.42 & 20.46 \\
\hline $\mathrm{SR}(\mathrm{cm})$ & \multicolumn{2}{|c|}{2.49} & 4.02 & 1.67 \\
\hline
\end{tabular}

AIC, Akaike's information criterion; $L_{50}, 50 \%$ selection mantle length $\left(L_{50}=-a / b\right)$; MLL, maximum log-likelihood; SR, selection range $\left(\mathrm{SR}=L_{75}-L_{25}=(2 \ln 3) b\right)$.

were calculated to be 259.64 in model A and 259.93 in model B. Model A had a slightly smaller AIC value than model $B$, and was therefore the betterfit model. This result means that the selection curves in 2002 and 2003 were expressed by a single logistic function, whereas estimates of parameter $p$ were different in the two years because the ratios of the fishing effort of the test gear to the control gear were not the same.

The selection curve of the trammel net for oval squid obtained with the estimates of the logistic parameters $a$ and $b$ in model A is shown in Figure 5 and is expressed by the following equation:

$$
r(l)=\frac{\exp (-18.57+0.88 l)}{1+\exp (-18.57+0.88 l)}
$$

From these logistic parameter estimates, the $50 \%$ selection mantle length and selection range $\left(L_{75}-\right.$ $L_{25}$ ) were calculated to be $21.07 \mathrm{~cm}$ and $2.49 \mathrm{~cm}$, respectively (Table 2 ).

According to previous reports, the size selectivity of a trammel net depends strongly on the relationship between the mesh perimeter of the inner net

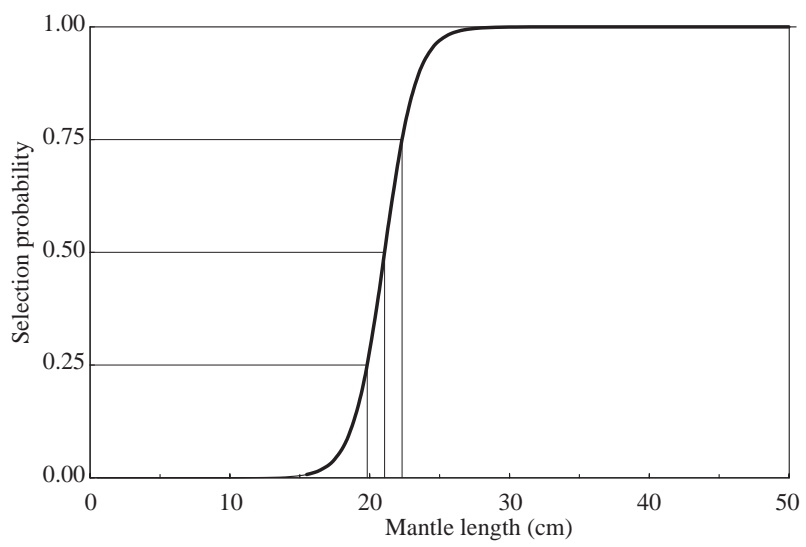

Fig. 5 Logistic selection curve for trammel net for herded oval squid.

and the body girth of the fish. ${ }^{8,12,13}$ The relationship between the mantle length $L$ and the mantle girth $G$ of oval squid is expressed by the following linear regression equation (Fig. $6 ; R^{2}=0.85, P<0.05$ ):

$$
G=0.698 L+4.12
$$

From this equation, the mantle girth of the $50 \%$ selection mantle length, $21.07 \mathrm{~cm}$, was calculated to be $18.83 \mathrm{~cm}$. The mesh perimeter of the inner net of the trammel net was approximated to be $17.06 \mathrm{~cm}$, twice the measured mesh size of $85.3 \mathrm{~mm}$ (Fig. 2). The mantle girth of the $50 \%$ selection probability was slightly larger than the mesh perimeter. In contrast, the selection probability of oval squid of $18.54 \mathrm{~cm}$ mantle length equivalent to girth $17.06 \mathrm{~cm}$ was 0.09 . The oval squid of mantle girth smaller than the mesh perimeter of the inner net passed through the mesh to escape from the net. This strongly supports the findings that the selectivity curve was appropriate.

Ueta reported that conservation of recruited stock is effective for resource management of oval squid. ${ }^{4}$ Small-sized oval squid can be protected by 


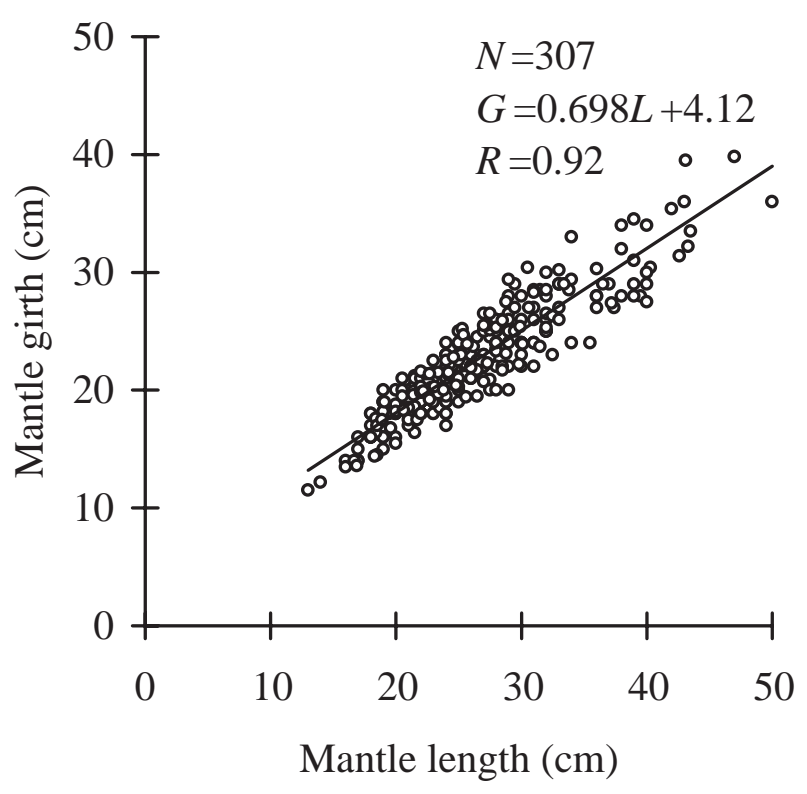

Fig. 6 Relationship between mantle length and mantle girth of oval squid. There is a significant correlation $(R=0.92, P<0.05)$.

applying the appropriate mesh size in trammel net fishery. To confirm the size selectivity of mesh size, comparative fishing experiments using trammel nets of various mesh sizes would be useful. It is also necessary to examine the survival of oval squid after escape from trammel nets.

Studies on the size selectivity of gill nets and trammel nets have been carried out with comparative fishing experiments using gear of different mesh sizes. ${ }^{7-12}$ However, Millar pointed out that in fishing gear with a bell-shaped selectivity curve (e.g. gill net and hook) it is impossible to determine a selectivity curve from comparative catch data only, and also that appropriate control fishing gear is necessary for analysis. ${ }^{18}$ In the present study, a set net of small mesh size was used as control gear for fishing gear selectivity analysis, and good results for trammel net size selectivity were obtained. Fortunately, a large number of set nets are operated in the coastal area around Japan. Set nets usually have final section of small enough mesh size to retain young small animals, and therefore can be good control gear not only for selectivity analysis, but also for sampling and monitoring gear. ${ }^{23}$

\section{ACKNOWLEDGMENTS}

We are deeply indebted to Mr Masaru Kikuchi, fishing master of the trammel net and the set net at the Nishizaki Fisheries Cooperative Association.

\section{REFERENCES}

1. Kaneda Y. Fisheries and Fishing Methods of Japan. Seizando, Tokyo. 1995.

2. Akiyama S, Kaihara S, Arimoto T. Capture characteristics of herding trammel net for oval squid Sepioteuthis lessoniana in Tateyama Bay, Chiba Prefecture. Nippon Suisan Gakkaishi 2004; 70: 865-871.

3. Tokai T \& Ueta Y. Estimation of size selectivity for oval squid Sepioteuthis lessoniana in the squid jigging fishery of Tokushima Prefecture. Fish. Sci. 1999; 65: 448-454.

4. Ueta Y. Fishery biological studies of the oval squid Sepioteuthis lessoniana around Tokushima Prefecture. Bull. Tokushima Pref. Fish. Exp. Stn. 2000; 1: 1-79.

5. Myhre RJ. Gear selection and Pacific halibut. Rep. Int. Pac. Hal. Comm. 1969; 51: 1-35.

6. Hovgard H \& Riget FF. Comparison of longline and trawl selectivity in cod surveys off West Greenland. Fish. Res. 1992; 13: 323-333.

7. Kitahara T. On sweeping trammel net (kogisasiami) fishery along coast of the Sanin district - III. Mesh selectivity curve of sweeping trammel net for branquillos. Nippon Suisan Gakkaishi 1968; 34: 759-763.

8. Koike A \& Takeuchi S. Effect of trammel net with different sizes of mesh of inside net on catching efficiency. Nippon Suisan Gakkaishi 1985; 51: 895-901.

9. Salvanes AGV. The selectivity for cod (Gadus morhua L.) in two experimental trammel-nets and one gillnet. Fish. Res. 1991; 10: 265-285.

10. Losanes LP, Matuda K, Machii T, Koike A. Catching efficiency and selectivity of entangling nets. Fish. Res. 1992; 13: 9-23.

11. Fujimori Y, Tokai T, Hiyama S, Matsuda K. Selectivity and gear efficiency of trammel nets for kuruma prawn (Penaeus japonicus). Fish. Res. 1996; 26: 113-124.

12. Purbayanto A, Akiyama S, Tokai T, Arimoto T. Mesh selectivity of a sweeping trammel net for Japanese whiting Sillago japonica. Fish. Sci. 2000; 66: 97-103.

13. Fujimori Y, Matsuda K, Losanes LP, Koike A. Water tank experiment on the catching efficiency and mesh selectivity of gillnets. Nippon Suisan Gakkaishi 1990; 56: 2019-2027.

14. Matsuoka T. A tank experiment on selectivity components of a trammel-net for Tilapia mossambica. Nippon Suisan Gakkaishi 1991; 57: 1331-1338.

15. Millar RB \& Walsh SJ. Analysis of trawl selectivity studies with an application to trouser trawls. Fish. Res. 1992; 13: 205-220.

16. Millar RB. Estimating the size-selectivity of fishing gear by conditioning on the total catch. J. Am. Stat. Assoc. 1992; 87: 962-968.

17. Xu X \& Millar RB. Estimation of trap selectivity for male snow crab (Chionoecetes opilio) using the SELECT modeling approach with unequal sampling effort. Can. J. Fish. Aquat. Sci. 1993; 50: 2485-2490.

18. Millar RB. The functional form of hook and gillnet selection curves cannot be determined from comparative catch data alone. Can. J. Fish. Aquat. Sci. 1995; 52: 883-891.

19. Tokai T \& Mitsuhashi T. SELECT model for estimating selectivity curve from comparative fishing experiments. Bull. Jpn. Soc. Fish. Oceanogr. 1998; 62: 235-247.

20. Uchida K, Tokai T, Mituhashi T, Hu F, Matuda K. Size selectivity of net-pot for white-spotted conger eel estimated 
from paired-gear tests with change in sampling effort. Nippon Suisan Gakkaishi 2000; 66: 228-235.

21. Hiramatsu K. A statistical study of fish population dynamics using maximum likelihood method - parameter estimates and model selection. Bull. Nat. Res. Inst. Far Seas Fish. 1992; 29: $57-114$.
22. Tokai T. Maximum likelihood parameter estimates of a mesh selectivity logistic model through SOLVER on MSExcel. Bull. Jpn. Soc. Fish. Oceanogr. 1997; 61: 288-298.

23. Tokai T, Sato R, Ito H, Kitahara T. Year-class strength of the ocellate puffer around a spawning area in the Inland Sea of Japan. Nippon Suisan Gakkaishi 1993; 59: 245-252. 